\title{
LA DEMOCRACIA REPUBLICANA: \\ PASADO Y PRESENTE ${ }^{1}$
}

THE REPUBLICAN DEMOCRACY:

PAST AND PRESENT

NATALIO R. BOTANA •

Natalio R. Botana es Profesor Emérito de la Universidad Torcuato Di Tella, CABA (Argentina).

Recordemos brevemente los orígenes de la tradición republicana en nuestro país y en América Latina.

Cuando se fueron decantando los efectos de las guerras de Independencia, a comienzos del siglo XIX, la tradición republicana que pusimos en marcha en nuestro continente tuvo en mira, por efectos queridos y no queridos, tres objetos simultáneos: establecer el Estado fijando sus fronteras territoriales; instaurar una forma de gobierno: república en Hispanoamérica, monarquía constitucional y después república en Brasil; y, por fin, desarrollar una sociedad civil que, de acuerdo con su definición clásica en los siglos XVIII y XIX, suponía el desarrollo de una economía. Si los actos de levantar un Estado evocaban la incógnita «hobbe- siana» consistente en reducir una pluralidad de poderes territoriales a la unidad de una organización suprema basada en la pertenencia obligatoria de habitantes y ciudadanos, las marchas y contramarchas de los regímenes políticos y de los cambios sociales remitían a los hallazgos del constitucionalismo y a las concepciones predominantes acerca de la sociedad democrática y de la sociedad industrial también llamada capitalista. Todo esto, que a primera vista parece cosa del pasado, está en estos días muy presente entre nosotros. Son las demoras propias de la sociedad industrial unidas a la fáustica irrupción de la sociedad digital y, como veremos de inmediato, son las turbulencias que, día tras día, sufren el Estado y los regímenes de democracia republicana.

${ }^{1}$ El siguiente texto reproduce la conferencia pronunciada el 4 de mayo de 2016 en la Universidad Nacional de Rosario con motivo del otorgamiento del Doctorado Honoris Causa. 
Subrayo pues los tres términos: Estado, régimen político y sociedad civil. Esta simultaneidad de propósitos es característica de nuestra tradición republicana, la tercera tradición en occidente luego de que comenzara en América del Norte (1776) y se prolongase en Europa a partir de 17891793. En la primera tradición, la palanca impulsora fue el antecedente de la praxis republicana, con o sin esclavitud, durante el período colonial; en la segunda, la consolidación en naciones como Francia de la soberanía del Estado, en tanto fenómeno previo al estallido revolucionario. Nosotros no contamos con esas palancas. Hubo que hacer las tres cosas a la vez: Estado, república y sociedad civil. Este comienzo abrió curso a un itinerario de dos siglos, como si los tres objetos, hoy como ayer, abriesen en conjunto un horizonte de legitimidad. La cuestión del Estado, del régimen político y de la sociedad civil tiene entre nosotros rotunda actualidad. Compartimos en Latinoamérica, pues, este punto de partida. Si hace medio siglo, las cuestiones más acuciantes eran las crisis que sufríamos en el nivel de los regímenes políticos con las dictaduras y la política armada, en la actualidad, resueltas parcialmente aquellas gravísimas perturbaciones, nos interpelan nuevas cuestiones. Las señalaré a continuación, pero antes quiero precisar lo que entendemos en esta conferencia por Estado, por república y, por extensión, por democracia republicana.
En su versión elemental, tantas veces citada, el Estado es una unidad política de pertenencia obligatoria que, dentro de límites territoriales, reclama la instauración del monopolio tanto de la fuerza legítima como de la recaudación fiscal. Este diálogo entre Weber y Schumpeter nos permite fijar un punto de partida en el análisis de nuestra circunstancia, pero no toma en cuenta los atributos complementarios ínsitos en una definición democrática y republicana del Estado: el atributo de la soberanía legal y limitada, que necesariamente encuadra las acciones tendientes a traducir libertades en derechos e instituciones, y el atributo que engloba otros bienes públicos dignos de ser promovidos y garantizados. A menor capacidad para instituir soberanías e incorporar bienes públicos a la vida en sociedad, mayor probabilidad de que este tipo de Estado caiga por la pendiente de una progresiva desintegración.

Si hablamos de la definición democrática y republicana del Estado, es porque la conjunción entre democracia y república que veremos de inmediato se ubica, hasta prueba en contrario, en un contexto estatal. Pero este contexto ha variado sustancialmente, pues está ubicado y hostigado por un contorno más amplio, el contorno de la globalización en el cual estamos inmersos. De aquí surge en la actualidad una contradicción mayor, porque mientras la economía, las comunicaciones y la cultura adquieren un perfil global, la de- 
mocracia republicana conserva un perfil nacional y estatal, sea éste de carácter unitario o federal. El ocaso del Estado nación es por tanto externo a nuestra circunstancia; no lo es, en cambio, en el plano interno de nuestros conflictos y armonías (por parafrasear a Sarmiento).

Vayamos a continuación a lo que entendemos por democracia republicana. La república es una forma de gobierno o régimen político que se refiere más al ejercicio del poder y a sus límites que al origen de éste, punto omega, como sabemos, de la teoría democrática. Cuando el origen democrático del poder se radica en la soberanía el pueblo en su sentido más amplio, la república haría las veces de un regulador del régimen sobre la base de seis componentes: 1) los derechos que se proclaman, 2) las instituciones que los garantizan, 3) el cuerpo representativo que en ese marco gobierna, 4) el gobierno que hace públicos sus actos, 5) la responsabilidad que esos representantes y gobernantes asumen y 6) las obligaciones que el ciudadano incorpora a su conducta para apuntalar ese complejo edificio. La democracia y la república conforman por tanto una unidad. La democracia sin república es una fuerza que no tiene puntos de referencia; la república sin democracia es una estructura vacía de contenido popular. En síntesis, una democracia republicana es una democracia que la ciudadanía ejerce conforme a derechos, reglas e instituciones.

Las reglas e instituciones no son factores pétreos, indemnes al cambio. Como en todo proceso democrático, están sujetas a modificaciones e impugnaciones a través de las cuales se van institucionalizando otros valores, nuevos intereses e inéditas relaciones de poder; pero en este incesante proceso, las tensiones que de él derivan provienen de una suerte de piedra de toque de la legitimidad republicana. $\mathrm{Si}$, en efecto, es necesario cambiar, ese cambio no es posible si no acatamos las reglas de juego establecidas. Como decía un politólogo de fama, a mediados del siglo anterior: conflicto en el régimen o conflicto por el régimen. La apuesta del reformismo republicano se juega dentro del régimen y no fuera de él.

Hechas estas aclaraciones, voy a las cuestiones a que he hecho referencia.

En primer lugar creo que deberíamos subrayar una tensión histórica, de rotundo impacto en estos días, entre los dos postulados sobre los que se asienta la república en una democracia, como señala Dominique Schnapper²: primero, los ideales abstractos y universales escritos muy pronto en nuestros estatutos provisionales y constituciones de una república

\footnotetext{
2 Dominique Schnapper, La democracia providencial. Ensayo sobre la igualdad contemporánea, Rosario, Homo Sapiens, 2004, pp. 15 y ss.
} 
de ciudadanos libres e iguales; segundo, las herencias históricas, étnicas, míticas, religiosas y culturales, que también conforman el vínculo social. El choque aún no resuelto entre ambos postulados despertó la imaginación política. Con ella hemos abonado toda clase de experiencias, desde designios revolucionarios hasta el proyecto reaccionario de eliminar por la fuerza aquel principio -verdadera promesa de la democracia republicana- de una comunidad de ciudadanos libres e iguales. La gran sacrificada en esta pretendida gesta entre extremos ha sido la ética reformista y el Estado que debería dar el marco de pertenencia obligatoria a este cometido.

En la actualidad, estas tensiones siguen presentes debido al influjo de varios fenómenos. Si en el pasado del siglo XIX la definición abstracta de la república produjo reacciones caudillistas y represiones racistas sobre las poblaciones nativas y la población esclava de origen africano, en los albores del siglo XXI corremos el riesgo de recorrer el camino inverso, que implica la dominación de una cultura sobre otra, dejando de lado el apetito de universalidad de los derechos y la riqueza del pluralismo. Vivimos actualmente, en algunos países más que en otros, un proceso de reconocimiento de postergaciones históricas y deudas pendientes. Esto se advierte en diversos lenguajes: en los lenguajes del indigenismo o en los lenguajes del na- cionalismo. El nacionalismo esencialista, fundado en excluyentes criterios étnicos, lingüísticos o religiosos, es hoy un desafío enorme tanto en América Latina como en Europa o Medio Oriente.

Para contrarrestar este desafío es necesario armar con estas piezas diversas, dotadas algunas de una violenta pulsión agonal, un nuevo pacto pluralista fundado en la inclusión y no en una dialéctica de exclusión. Ahora se ha puesto de moda la palabra inclusión. El problema consiste en saber qué tipo de régimen republicano habrá de acoger a los excluidos en las márgenes y que, al incorporarse, amplían la esfera de la ciudadanía. Incorporarse a qué; incorporarse para transformar qué cosa. Ya lo dijo Tocqueville: la igualdad, que seńalo es la fuerza motora de la inclusión, puede combinarse con las libertades o puede hacerlo a despecho de las libertades. Pienso que este problema no está del todo resuelto en América Latina.

En segundo lugar, es claro que en el plano normativo, los proyectos de integración, tanto regionales como subregionales (hoy en discusión en Europa y aletargados en el Cono Sur), significan una reformulación del Estado y llevan implícito el objetivo de instaurar la "paz perpetua» a que aludía Kant en el extenso espacio de nuestra región. Kant decía que la posibilidad histórica de instaurar un pacto de paz perpetua entre los Estados 
dependía de una condición necesaria. Vale decir: de la constitución republicana de los Estados que intervienen en ese pacto. Dicha constitución se establecía conforme a tres principios. Primero, el de la libertad de los miembros en cuanto seres humanos; segundo, el de la dependencia de todos respecto a una legislación común; tercero, el de la igualdad de todos en cuanto ciudadanos. Con excepciones, me parece que hemos alcanzado niveles razonables de libertad política si comparamos estos logros con el período de las dictaduras; pero padecemos privaciones evidentes (algunas son fallas geológicas) en cuanto a los niveles de sujeción a la ley y a los niveles de igualdad como ciudadanos. La igualdad ante la ley, función irrenunciable del Estado de derecho, respaldada por las adquisiciones de derechos económico-sociales, ha sido la meta que nos planteamos, al menos, desde el último medio siglo. Meta aún lejana. En este punto no estamos bien, pese a los progresos alcanzados. Esto requiere, entre otros objetivos, echar las bases de una política de adhesión a la ley legítima en el contexto de la megalópolis latinoamericana.

En tiempos de la Independencia hace dos siglos, poco antes de su asesinato, el Mariscal Sucre presentía el impacto de una «aristocracia militar» que «apoderándose del mando en todas partes, hacía gemir al ciudadano por un absoluto olvido de las garantías y derechos». Después de innumerables pruebas, hoy nos hemos desembarazado de aquel fardo, pero la anarquía belicosa que siempre impregnó el mundo rural en América Latina se manifiesta de nuevo en nuestras megalópolis: ese universo urbano formado vertiginosamente en el último medio siglo, donde conviven varios planos superpuestos: las luces de la ilustración -ciencias, arte y espectáculo-, las luces de la opulencia junto con el ascenso de las clases medias, nuevas o viejas, en fin, la oscuridad de la exclusión. Todo junto, arremolinado en un espacio estrecho, muy estrecho, en el cual coexisten ya poblaciones que superan holgadamente los diez millones de habitantes y hasta los duplican. Cuatro de nuestras megalópolis -una en México, otra en Argentina y dos en Brasil- ya suman probablemente en total más de sesenta millones de habitantes. Las megalópolis son pues grandes urbes escindidas. De seguir este proceso de expansión de las megalópolis, esta será en los años venideros la materia sobre la cual habrá que delinear la fisonomía de una democracia republicana. Es un cambio de escala frente al cual no podemos permanecer indiferentes (añado al pasar que la cuestión de la escala más conveniente para perfeccionar un régimen republicano, siempre ha despertado la atención de la teoría política, desde Montesquieu hasta nuestros días).

En este ámbito de urbes escindidas, 
como las llamó José Luis Romero ${ }^{3}$, se manifiestan tres comportamientos que están oxidando, obviamente en algunos países más que en otros, el resorte que impele al cumplimiento de la ley. Son los comportamientos que fracturan el circuito de la coacción; los comportamientos que rompen el circuito de la confianza; y los comportamientos que corrompen la administración del Estado merced a una concepción patrimonialista y corrupta de la cosa pública. Los tres comportamientos son factores que erosionan tanto la legitimidad republicana como la legitimidad de la representación política.

No es necesario explayarse en detalle para señalar que nuestros regímenes en América Latina contienen uno de los niveles de desigualdad y violencia social más altos del mundo; que los niveles de confianza en los jueces y policías, en los parlamentos, servicios públicos y partidos políticos están por debajo del 30\% (datos de Latinobarómetro), y que los escándalos de corrupción están estremeciendo las bases de idoneidad y calidad ética de la administración pública. Estas malformaciones plantean una contradicción entre realidades e ideales: la lógica de un régimen colonizado por estos hechos de corrupción -pensemos en Argentina y Brasil- es opaca; la lógica republicana de la democracia pretende ser, en cambio, transparente. Pero hay algo más, porque el Estado no es solamente una estructura de dominación, sino que debería ser una estructura capaz de irradiar confianza.

Creo, en este sentido, que la revolución digital puede hacer del Estado una agencia mejor capacitada en la gestión y el control del servicio público. Las grandes interpretaciones en cuanto al Estado y a la estatalidad olvidan a veces el lado cotidiano del Estado que, si es bien atendido, puede mejorar la confianza hacia lo público. Hoy la confianza en América Latina se ha apartado del Estado y circula por instituciones pre-políticas o parapolíticas: las iglesias, la familia, los vecindarios, las asociaciones espontáneas, las ONG, los movimientos sociales. Señal de que la confianza se está desplazando hacia otro lado, no hacia la cosa pública, que es el corazón de la tradición republicana, sino hacia la cosa privada o hacia una combinación de lo público con lo privado.

Por otra parte, las promesas de mejora estatal gracias a las nuevas tecnologías conllevan un aspecto negativo, porque la revolución digital se ha convertido en un arma poderosa y paradójica. De un lado, acrecienta el control del Estado sobre los habitantes; de otro, la acción de quienes penetran redes secretas de impunidad

${ }^{3}$ Véase José Luis Romero, Latinoamérica: las ciudades y las ideas, Buenos Aires, Siglo XXI, 1976, cap. 7. 
-evoco el caso reciente de los «Panama Papers»- pone al descubierto el lado perverso de la globalización financiera y de la ruptura del pacto fiscal. Planteo el desafío: ¿es acaso posible, con los controles civiles de la tradición republicana que hemos heredado, poner límites tanto a estos avances sobre la intimidad y las libertades personales, como al colosal flujo, legal e ilegal, de las transacciones financieras? Dejo la pregunta abierta sin desconocer el hecho no menos preocupante de la concentración de los flujos de información en pocas y poderosas empresas tecnológicas de planetaria irradiación.

Adviértase que estos fenómenos no son patrimonio exclusivo de América Latina, pues se trata de procesos de carácter mundial, pero lo que nos singulariza y emparenta con otras regiones es el hecho de la megalópolis escindida tanto por las desigualdades como por las oligarquías armadas del delito organizado y por las oligarquías de la corrupción que también, como decía Sucre, hacen gemir al ciudadano. En este desafío se condensan los logros y fracasos de la representación política en América Latina. Tal vez encontremos en este punto una agenda compartida: la de levantar el reto del gobierno de repúblicas representativas montadas sobre un escenario que, muchas veces, remeda un gigante invertebrado. Acaso sin darnos cuenta hemos invertido el argumento de Hobbes: la violencia urbana en América
Latina no es pre-política; es, al contrario, política porque marca a fuego la insuficiencia de las instituciones.

Por otra parte, la sujeción a una ley común, capaz de generar una distribución más igualitaria de la libertad, requiere una coincidencia práctica, que ya hemos señalado, entre legitimidad de origen y legitimidad de ejercicio. Este vínculo se está desgastando a caballo de una tendencia que recorre algunos países en América Latina y que busca vaciar nuestros regímenes en antiguos moldes, típicos del hiper-presidencialismo. Tras la reivindicación de los «verdaderos» o «auténticos» intereses del pueblo, esta forma unanimista de dominación busca controlar las libertades constitucionales para someterlas a los dictados -me atrevo a parafrasear a Maquiavelo- de unos pretendidos "príncipes nuevos».

Como se deduce de estos comentarios, no estaríamos confrontando en estos años el modelo clásico de corrupción ideológica de los regímenes democráticos y republicanos. Hoy, en cambio, estaríamos más cerca de un escenario en el cual las incongruencias y alteraciones en lo que se refiere al ejercicio republicano de la democracia llegan a generar metástasis institucionales. Por eso, los conflictos a que hemos aludido abren interrogantes acerca del porvenir de la representación política. Este, creo yo, es un punto crucial a la altura del siglo XXI. Como decíamos 
al comienzo de estas reflexiones, ¿podrá, en efecto, el régimen de democracia republicana hacer frente al desafío que la mutación planetaria en curso - mutación social, económica y cultural- plantea a la representación política de los ciudadanos?

Para intentar alguna respuesta, ensayemos una triple distinción. En los regímenes democráticos del siglo xxI se conjugan, muchas veces en conflicto, la dimensión electoral, la dimensión institucional y, en el horizonte utópico de esta forma de gobierno, la dimensión igualitaria y fraterna de la ciudadanía.

Entre estas tres dimensiones la que más resalta, casi como si fuera una práctica cotidiana, es la dimensión electoral. Votamos, elegimos, a simple vista los partidos compiten envueltos en un mundo de sondeos y encuestas de opinión que escrutan las demandas de la sociedad; pero, acaso sin darnos cuenta, no percibimos del todo como también está cambiando la escala de la representación, como si se tratase de un repliegue del ciudadano sobre sí mismo que, con el concurso de las redes sociales, crea él mismo su propio sistema de representación. Si la representación política fue concebida atendiendo a la mediatez entre gobernantes y gobernados, las redes sociales ponen hoy en agenda el carácter inmediato de la vida pública y privada. Tras estos itinerarios comunicacionales, que se arman y rearman con inusitada velocidad, impre- visibles sin duda hasta hace muy pocos años, está cambiando aceleradamente la percepción del tiempo y del espacio de la acción humana.

De esta manera, se están dejando de lado los vínculos tradicionales de mediación entre el ciudadano y el Estado, lo cual hace que las demandas y expectativas terminen volcándose de manera directa sobre la arena pública. Estas expresiones son tributarias de un descontento, sordo o manifiesto, con la insuficiencia de la democracia institucional y el carácter republicano de la misma. ¿Por qué digo esto? Porque la democracia institucional es la bisagra que abre el comportamiento electoral hacia una democracia de ciudadanos; vale decir: si, en este contexto radicalmente novedoso, la democracia electoral no produce instituciones que respondan a la demandas inmediatas de la ciudadanía de bienes públicos, el Estado se estremece y hace las veces de una organización fofa, con bolsones de corrupción, estancada y poco flexible. De aquí que deben ser bienvenidas la reformas que puedan efectuarse en el plano jurídico para ir salvando las distancias entre democracia electoral y democracia institucional. Sin embargo, no todo lo que reluce en las normas se refleja en las realidades cotidianas. Los cuerpos de leyes son frondosos; las adecuaciones vitales a la normas mucho más escuálidas.

Este es un problema que enlaza nuestros 
pasados con el presente. Siempre brilló en América Latina un genio caligráfico en la producción legislativa que sobrevolaba los privilegios sociales establecidos y no aterrizaba en el campo de las conductas. Desde las primeras constituciones del XIX, tan bellamente escritas, hasta las actuales, $\tan$ generosamente abiertas a la incorporación de un amplio espectro de derechos, nuestros regímenes no han elaborado todavía un razonable compromiso entre derechos y obligaciones. La experiencia no debería caer en saco roto porque de lo que se trata es de pasar de los derechos escritos a los derechos instituidos y de estos a las obligaciones asumidas por la ciudadanía. Son tres escalones a través de los cuales se puede subir o bajar. Este es un desafío enorme para la democracia republicana, porque en este mundo en transformación, la visión de un ciudadano creador de derechos y obligaciones libre y espontáneamente asumidas, también se está transformando. Desde luego, esto repercute en el porvenir de nuestros partidos políticos. Se ha dicho durante gran parte del siglo XX que la democracia republicana es un régimen de partidos. ¿Lo es todavía?

Para mí es claro que deberíamos reformular un nuevo pacto representativo en un momento histórico en este aspecto poco favorable. Debemos obrar pues a contracorriente. Quizás esta inédita envoltura de la mediación política, endeble y con otro tono, obedezca también al vacío de ideas públicas que, en general, se advierte en el mundo. La política hoy avanza a remolque de fáusticas mutaciones culturales, valorativas y tecnológicas. Mientras la sociología à la page se aplica a describir estos fenómenos mediante adjetivos como «leve», «líquido» o «fragmentario», la política prosigue razonando a la sombra de grandes principios elaborados en siglos anteriores. Si el XVIII y el XIX nos transmitieron los principios de los derechos individuales, de la representación política derivada de la soberanía del pueblo y de la división de poderes, el siglo XX, junto con los derechos sociales, trajo la novedad del partido político en tanto centro de convergencia de valores, intereses e ideología. Con su organización duradera, que no se confundía con la biografía de sus fundadores sino que la trascendía, el partido político dio cuerpo a dos clases de regímenes: los regímenes democráticos de carácter constitucional pluralista (así los llamó Raymond Aron), dotados como he dicho de derechos sociales, y los regímenes de dominación totalitaria. Así, el partido político fue la envoltura de la sociedad industrial cuando esta adquirió su plena madurez: los partidos políticos eran, en suma, organizaciones permanentes que incorporaban en su seno fuerzas sociales. La rapidez de los cambios ha demolido muchos aspectos de esta experiencia. Los partidos son ahora organizaciones más frágiles, en no pocos casos mucho 
más atentas a las demandas sociales que a las ofertas programáticas emanadas de sus liderazgos. Lo mismo vale, analógicamente, para los principios y fundamentos. Cuando permanecen como principios de legitimidad de alcance universal (por ejemplo, los derechos humanos) se los suele reivindicar en las democracias como un dato adquirido, muchas veces desligado del conjunto de obligaciones ciudadanas que dichos derechos suponen, y olvidando de paso la larga y dolorosa historia ínsita en sus comienzos, en su ampliación $y$ en su perfeccionamiento. Esta referencia a los derechos muestra a las claras, la extraordinaria circunstancia en que actualmente está situado este venerable patrimonio histórico. Seńalo este punto con énfasis porque, más allá de la discusión en torno a la definición del derecho - una discusión que lleva siglos- no me cabe duda alguna de que el sujeto que hoy forma la ciudadanía en las democracias republicanas es un sujeto histórico que, por ser tal, viene adquiriendo progresivamente un conjunto de derechos que conforman y dan sentido a su dignidad.

Primero fue el derecho a la vida y a la seguridad física. En segundo lugar, se incorporaron los derechos civiles y políticos. En tercer lugar, el derecho a la educación común y obligatoria. En cuarto lugar, el derecho a la salud. En quinto lugar, los derechos atinentes a la seguridad social y al combate contra la pobreza. En sexto lugar, en fin, los derechos que reclaman protección frente al desempleo. Este sexteto no tiene la armonía de una pieza musical sino que se radica en un escenario conflictivo indisolublemente vinculado al contrato fiscal que sustenta los Estados, al rendimiento de la economía y a la apertura hacia nuevas dimensiones, entre ellas la ecológica, las de género $y$, sin cerrar la lista, a las nuevas concepciones en torno al matrimonio y la familia. El sexteto pues se amplía constantemente. Lo que no se amplía con tanta aceleración son sus bases materiales. Aunque suene a lugar común, y esto los saben muy bien los gobernantes y hombres de Estado, los derechos cuestan dinero y enfrentan a diario profundos cambios en su contenido y en la manera como son asumidos por la conciencia ciudadana. Señalo, al respecto, la transformación por la que atraviesan el derecho a la educación y las tradicionales concepciones, tan caras en el Río de la Plata a partir del siglo XIX, del papel del magisterio, en la mayor o menor autoridad de los maestros en tanto referentes sociales, y en el rol de los medios tecnológicos puestos a su servicio.

Empero este análisis debería completarse desde otro ángulo porque, tratándose de un fenómeno histórico, los derechos suponen una escala a través de la cual se puede ascender o se puede descender. Mi generación y las camadas de estudiantes más jóvenes hemos sido educados a la sombra del antiguo criterio de que los de- 
rechos son acumulativos; es decir, aprendimos la teoría, o la dimos por supuesta, que asumía que la conquista de un nuevo derecho se hacía sobre la consolidación de los derechos ya adquiridos. Un recorrido fecundo que nos lleva de Hobbes a Rousseau, de estos a los pedagogos y administradores de la salud y, por fin, a los responsables de las agencias del Estado consagradas a la seguridad social. Pero, ¿qué pasa, por ejemplo, cuando la adquisición de derechos bienvenidos, como el de la igualdad de género o el matrimonio igualitario, se instalan sobre el terreno cenagoso de la inseguridad y del crimen organizado? Ocurre que la imagen de la acumulación de derechos se quiebra y, al modo de un filme retrospectivo, afrontamos, como si fuera una rotunda novedad, que se impugnen crudamente derechos tributarios del pacto "hobbesiano» o propios de lo que en el siglo XIX se denominaba Estado gendarme. Ascenso y descenso: todo en simultáneo. Celebramos los nuevos derechos y contemplamos, o más bien sufrimos, el deterioro de la plataforma básica sobre la cual, vuelvo a Max Weber, se levantaron los Estados nacionales.

Y hablando de plataforma básica, tal vez convenga ilustrar estos problemas con dos referencias personales. Hace ya más de medio siglo, cuando realizaba mis estudios de doctorado en aquella Unión Europea en plena formación, la recaudación media fiscal de los seis países que ha- bían firmado hacía pocos años el Tratado de Roma era del $25 \%$ del PBI. Con ella se financiaban los bienes públicos de la educación, de la salud y de la seguridad social para una población -prestemos atención a este dato- cuya esperanza de vida al nacer se ubicaba en los setenta años. Hoy, la adquisición de estos bienes públicos es mucho más cara mientras la presión fiscal no cesa de aumentar junto con la evasión fiscal, y la esperanza de vida se ha empinado diez años más hasta los ochenta años. ¿A qué aludimos con este ejemplo? Al hecho de que hoy en día la satisfacción de los derechos requiere llevar a cabo un difícil ensamble con la economía, la demografía y la fiscalidad. En su defecto, como hoy observamos en Europa, cunde el desaliento, el descreimiento y la adhesión hacia las llamadas «utopías regresivas»; esto es: una vuelta de campana que nos sumerge en lo peor del pasado, en la contra-ilustración con su secuela de nacionalismos, racismos y odio al extranjero en la figura del inmigrante.

El segundo ejemplo es más cercano y ratifica el anterior. En 1984, con el fervor que nos suscitaba la instauración de la democracia, me tocó visitar California y a su gobernador Jerry Brown, un político del Partido Demócrata varias veces reelecto con intervalos. Cuando le transmitimos nuestro entusiasmo, Brown nos preguntó a boca de jarro: "¿quieren realmente consolidar una democracia?» $\mathrm{Y}$ añadió: 
«tengan en cuenta que es un régimen muy caro porque mientras las demandas populares son ilimitadas, los recursos fiscales son escasos». Esta es una lección trascendente que se acrecienta entre nosotros en la medida en que la legitimidad de la moneda, como la llamó Hugo Quiroga ${ }^{4}$, tambalea y se diluye debido a los procesos inflacionarios, a la evasión fiscal, a la economía en negro y, en fin, a las tenazas opresivas de la desconfianza pública.

En la tradición republicana esta permanente reconversión y declinación histórica de los derechos tiene su contrapartida en la estructura de mediación de los partidos. Aunque suene a otro lugar común, los derechos son institucionalizados por los parlamentos donde legislan representantes propuestos por partidos. $\mathrm{Y}$ aunque suene, insisto, a argumento repetido y en medio de las transformaciones sociales y culturales que hemos revisado brevemente, nada, en efecto, ha logrado, por ahora, suplantar en las democracias del siglo XXI el rol mediador de los partidos. Hoy un régimen con partidos frágiles o facciosos presenta la imagen de un Estado inerme $o$, en el otro extremo, presenta la silueta de un Estado inclinado a dar albergue, en reemplazo del faccionalismo, a formas poco complacientes con una práctica sincera del pluralismo político y de la alternancia entre oficialismo y oposiciones. Estas dos señales negativas nos muestran que, más allá de la crisis que los aqueja, los partidos siguen siendo indispensables. Un desafío gigantesco y a la vez paradójico: declina lo que es aún indispensable. Por este motivo, en ausencia de un sistema de partidos que mantenga viva la llama de la renovación, los contenidos republicanos de la democracia se degradan. En consecuencia, los regímenes en los cuales prevalece el talante institucional, la atmósfera ética que rodea a los dirigentes y la capacidad para mantener de pie sus sistemas de partido, serán los que, posiblemente, podrán avanzar mejor en este mundo preñado de incertidumbre. Desprestigiados y a la vez necesarios, los partidos deberían por tanto recuperar las ganas para plasmar ideas a través de la acción. Es un reto a la inteligencia práctica que hoy parece haber desertado de los debates. Añadiría: es el reto de dar a luz una nueva versión del arte de combinar valores. La historia nos enseña que los regímenes de democracia republicana giran en torno a los valores de libertad, igualdad y justicia. No hay vueltas: esta es nuestra trilogía. Si bien jamás obtendremos de ella una síntesis perfecta, la trama de nuestra existencia cívica no debería dejar nunca de lado esta exigencia de combinar valores. Uno de los riesgos que actualmente planea sobre nuestra circunstancia es precisamente el de recaer -ya lo hemos

${ }^{4}$ Véase Hugo Quiroga, La Argentina en emergencia permanente, Buenos Aires, Edhasa, 2005, cap. 3. 
hecho en muchas oportunidades del pasado- en la manía de la simplificación y en la arrogancia de creer que la política auténtica se cifra en la pretendida imposición de un valor en detrimento de los otros. En algunos de nuestros países hemos aprendido esta lección; en otros no. Sería deseable que esta visión tolerante de la vida, que no rehúye el conflicto sino que lo asume y encauza hacia un horizonte más humano, se proyecte en estos años.

\section{Registro bibliográfico}

BOTANA, NATALIO R.

"La democracia republicana: pasado y presente», en: ESTUDIOS SOCIALES, revista universitaria semestral, año XXVI, n 51, Santa Fe, Argentina, Universidad Nacional del Litoral, julio-diciembre, 2016, pp. 17-29.

\section{Descriptores · Describers}

democracia / república / representación política / América Latina

democracy / republic / political representation / Latin America

Recibido: 15 / 05 / 2016

Aprobado: 23 / 06 / 2016 